\title{
Prescribing practices of community child and adolescent psychiatrists
}

\author{
AIMS AND METHOD \\ A questionnaire was sent to all 55 \\ community child and adolescent \\ psychiatrists working in the West \\ Midlands to examine the prescribing \\ practices of community child \\ psychiatrists, because most previous \\ studies have included prescribing \\ data from specialist (tier 4) services. \\ RESULTS \\ The survey had a good response \\ rate $(87 \%)$. The vast majority of child
}

\author{
psychiatrists were prescribing \\ stimulants and antidepressants, and \\ over half were prescribing \\ antipsychotics and melatonin. At \\ least half of the consultants would \\ consider prescribing an antipsychotic \\ for the treatment of aggressive \\ behaviour. One-third of consultants \\ cited pressure on services as a reason \\ for prescribing medication.
}

\author{
CLINICAL IMPLICATIONS \\ Community child psychiatrists were \\ prescribing more medication than \\ expected, which may have a \\ considerable impact on referral rates \\ to adult services in the future. It is \\ concerning that the increased use of \\ medication may be a reflection of \\ pressure on services.
}

Psychopharmacological treatments for children and adolescents have become increasingly widespread in the USA over the past two decades (Popper, 2002). For example, the use of stimulants in youths more than doubled between 1990 and 1995 (Safer et al, 1996).

Data on the prescribing practices of child psychiatrists in the UK are very limited. Reported prescription rates generally have been low (Bramble, 1992, 1997; James, 1996) but there has been some increase, especially in the number of psychiatrists prescribing stimulants and in the use of newer antidepressants (McNicholas, 2001). If this trend continues it may have a serious impact, not only on child psychiatry, but also on adult mental health services, which in the future may have to deal with increasing numbers of referrals from child psychiatry of children on medication once they reach 16-18 years of age.

Some drugs, such as melatonin, are being used increasingly by child psychatrists in the UK but have received little attention in the literature so far; for example, melatonin has been examined only in one study (Johnson \& Clark, 2001) where its reported use was low. Also, many studies so far have looked at one drug class only - antidepressants (Bramble, 1992), stimulants (Bramble, 1997), antipsychotics (Slaveska et al, 1998; Ram \& Vanstrallen, 1999) - and all have included prescribing data from specialist services, which may artificially inflate prescription rates.

This study, therefore, specifically examined the prescribing practices of community (tiers 2 and 3) child psychiatrists to establish whether a similar trend of increased prescribing is apparent.

\section{Method}

An anonymous questionnaire was sent to all 55 community child and adolescent psychiatrists ( 35 consultants, 13 middle-grade doctors, 7 specialist registrars) working in the West Midlands region in May 2001. The region covers approximately $10 \%$ of the UK population (Office for National Statistics, 2000). Doctors working in specialist (tier 4) services were excluded (e.g. doctors working in in-patient units or the regional language unit).

The questionnaire included demographic details (job title, full- or part-time, number of months in present post) and some introductory questions about willingness to consider medication for a number of conditions. The psychiatrists were asked about the use of the three main drug classes (stimulants, antidepressants, antipsychotics), melatonin and drug combinations. This included questions on how many patients they were currently treating with each of the above medications and how many they had started in the past 6 months. There were also questions on the use of medication for the treatment of aggressive behaviour. Finally, the participants were asked to comment on their views about the development of drug use in child psychiatry in recent years. 
The questionnaire was piloted at a local audit group of child psychiatrists who suggested some minor

original papers amendments.

\section{Results}

Of the 55 psychiatrists surveyed, 48 responded (87\%), of which 30 were consultants, 11 were staff-grade doctors and 7 were specialist-registrars. Of the respondents, 92\% were currently prescribing stimulants, $88 \%$ were prescribing antidepressants, $63 \%$ were prescribing antipsychotics and $56 \%$ were prescribing melatonin. There was wide variation in the number of patients treated by

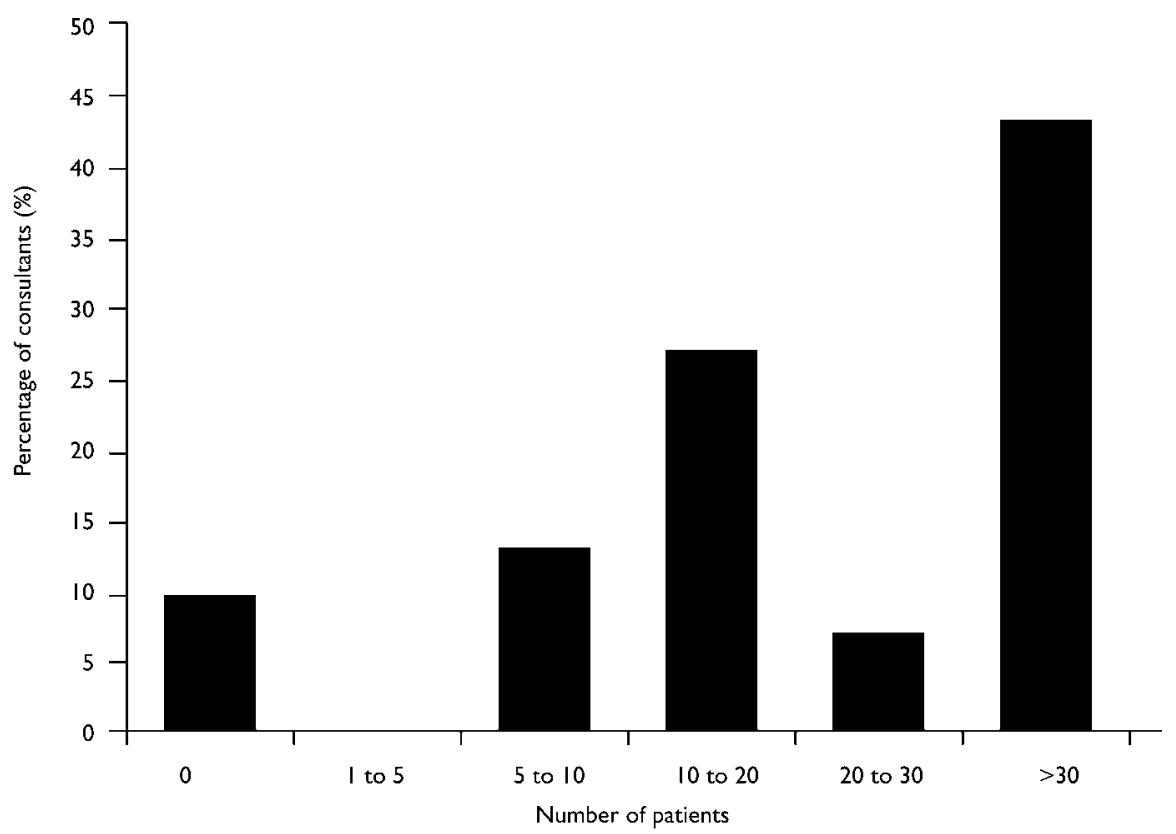

Fig. 1 Number of patients currently treated with stimulants by consultants.

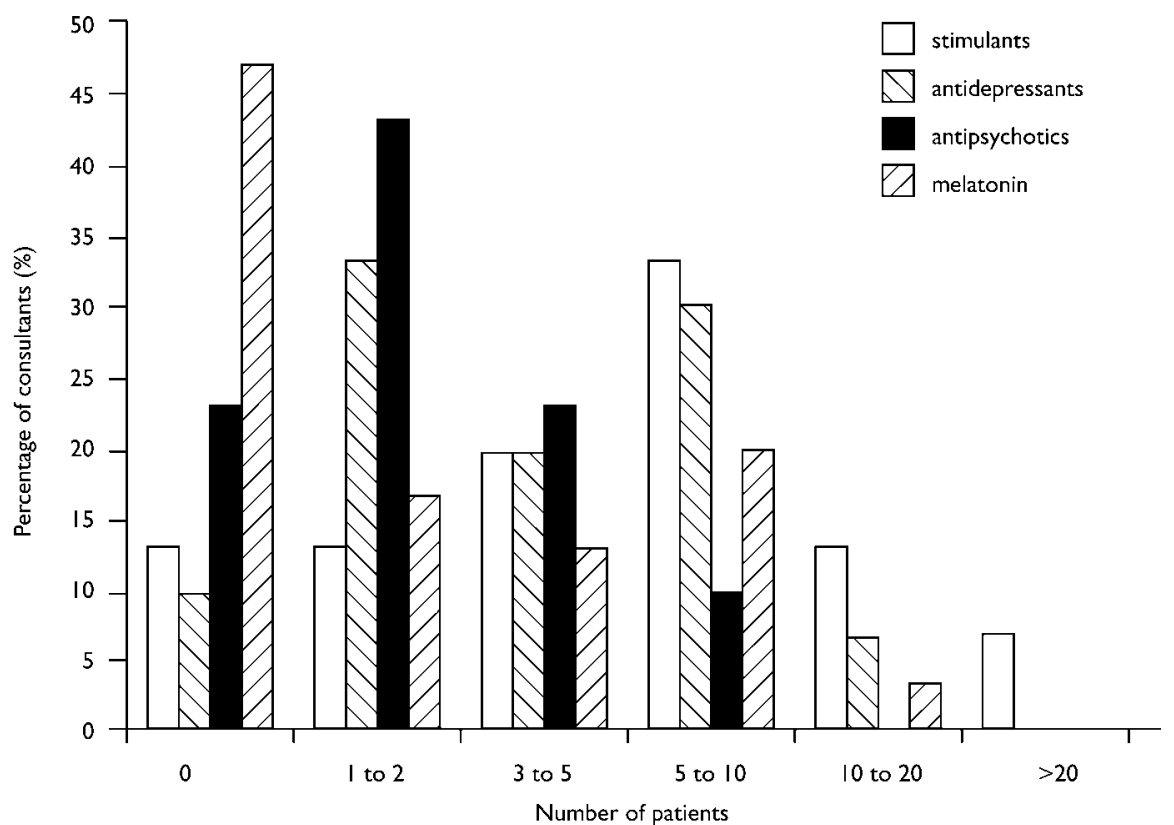

Fig. 2 Number of patients started on medication in the past 6 months by consultants. 
(23\%) had used medication frequently (i.e. started at least 10-20 patients in one of the drug classes) in the past 6 months.

Of all the respondents who had used stimulants in the past 6 months, $60 \%$ had started at least 5-10 patients on them (fig. 1) and two had started more than 20 patients. Of all participants, 85\% said that they were using selective serotonin reuptake inhibitors (SSRIs) as first-line treatment for depression; paroxetine was the most popular choice. Only one consultant specifically said that he/she would use a tricyclic (dothiepin) as first-line treatment. Half of the consultants would consider prescribing an antipsychotic for the treatment of aggressive behaviour, $87 \%$ of whom cited risperidone as the drug of choice. Although the actual number of patients treated with antipsychotics for aggressive behaviour was low, four consultants (13\%) indicated that they were treating 10 patients or more in that manner. Two-thirds of the consultants said that they were using melatonin and seven (23\%) had started at least 5-10 patients on it in the past 6 months. Melatonin was mainly used for sleep disturbance in autistic spectrum disorders and attentiondeficit hyperactivity disorder (ADHD).

Nearly a third of consultants said that they would never use polypharmacy, $60 \%$ said that they were combining two drugs and 30\% said that they would use three drugs (antipsychotics, stimulants and melatonin) simultaneously. Nearly all participants felt that there had been an increase in the use of medication in recent years. Perceived reasons for the increase were an increased evidence base for the efficacy of medication and an increase in the diagnosis of ADHD. Half of the consultants voiced some concern about the increase. A quarter felt that there was pressure from parents and the public to prescribe and one-third cited general pressure on child and adolescent mental health services (CAMHS) and a lack of resources.

\section{Discussion}

This survey had a high response rate and therefore should reflect the prescribing habits in the region. The main limitation of the study is that the data are retrospective and rely on estimations of how many patients were treated during the previous 6 months. We also examined one region only, which may prevent generalisation to all child psychiatrists in the UK, although we have no reason to suspect that our child psychiatry services differ greatly from other regions. On several occasions we excluded specialist registrars and staff-grade doctors from the evaluation. Specialist registrars tend to have lower caseloads and also a different case mix than consultants because of their training needs. Some of the staff-grade doctors were working only very few sessions or had a specific remit (e.g. an ADHD clinic). On other occasions all respondents were included to provide on overview of how much medication the tier 3 service in this region is prescribing.

The study demonstrated that community child psychiatrists appear to be prescribing more medication than documented in previous studies. In the most recent national survey, a third were using medication rarely or never and $87 \%$ had prescribed medication (McNicholas, 2001 ) in the past 6 months, whereas in our study $97 \%$ of consultants had used medication in the past 6 months and only $13 \%$ had used it rarely. However, this is likely to reflect a nationwide trend of increased prescribing. This is documented, for example, in the increased use of stimulants over the years. In a study published in 1996 (James, 1996) only $29 \%$ of participants were prescribing stimulants but this figure rose to $52 \%$ (Bramble, 1997) and eventually to $78 \%$ last year (McNicholas, 2001). The previous studies also suggested that the overall number of patients treated with stimulants was low (e.g. a mean of 3.2 patients started in the last year; Bramble, 1997), whereas in our survey $60 \%$ of the respondents who had used stimulants in the past 6 months had started at least 5-10 patients within that time period. This again most likely reflects a national trend. Even though one of the studies looked at a specific UK region (James, 1996) and others have employed differing methodology to ascertain child psychiatrists throughout the UK (Bramble, 1997; McNicholas, 2001), it seems highly unlikely that the reported increase in prescribing can be explained solely by methodological differences and probably reflects a true increase.

Compared with our study, one earlier study reported a similar proportion of psychiatrists prescribing antidepressants (Bramble, 1992) but a more recent study found a lower percentage (McNicholas, 2001). Nevertheless, it seems that they are now used for more patients than previously when child psychiatrists indicated that they started only one or two patients on antidepressants each year (Bramble, 1992). This study also confirms the trend to use SSRIs (James, 1996; McNicholas, 2001) rather than other classes of antidepressants.

Concerning the use of antipsychotic medication in child psychiatry in general, our survey showed a preference for atypical antipsychotics (mainly risperidone) rather than conventional antipsychotics. This finding is in contrast to a previous study (Slaveska et al, 1998) but similar to another survey (Ram \& Vanstrallen, 1999). Whereas in Slaveska's study only $30 \%$ of respondents were using antipsychotics for non-psychotic conditions (which also included Tourette syndrome), in our study $50 \%$ were considering the use of antipsychotics for the treatment of aggressive behaviour alone. Concern about the use of antipsychotic medication to treat aggressive behaviour has been voiced previously (Kaplan et al, 1994), mainly because of the side-effects of conventional antipsychotics. This is probably less of an issue with atypical antipsychotic medication and there is recent evidence from double-blind placebo-controlled trials that risperidone is effective in the treatment of aggressive behaviour in children and adolescents (Findling et al, 2000; Aman et al, 2002; McCracken et al, 2002). However, there is little knowledge about their potential long-term side-effects (Lynn \& King, 2002), particularly in children.

In our study, two-thirds of the consultants were using the unlicensed drug melatonin and $23 \%$ had started original papers 


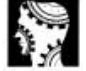

original papers at least $5-10$ patients on it in the past 6 months. This is a much higher rate than in the only other study that specifically examined the use of this medication (Johnson \& Clark, 2001). In that study, melatonin accounted for 8/ 478 prescriptions issued by 21 CAMHS in the North Western region of the country during a 6 -month period. Polypharmacy also was more common in our study than previously reported (McNicholas, 2001).

Overall, this study demonstrates widespread but highly variable use of medication in tier 3 CAMHS in the West Midlands region. As already highlighted by a recent publication by the Royal College of Psychiatrists, these differing practices, especially with regard to stimulant medication, are of concern (Coghill, 2001).

Although the reasons for such wide variation in prescribing practice were not investigated in this study, there are a number of possible hypotheses that should be investigated in further studies. A variety of patient/ population factors or clinician/service factors may underlie this variation. Although the services involved in this study provide care to similar age ranges of children, the social and demographic features of the populations served vary, with some services differing markedly with regard to the degree of social disadvantage within their catchments. Important clinician and service factors contributing to the variation are likely to include individual training and confidence in the use of various psychopharmacologies, the therapeutic models used and the local access to psychosocial treatments and inputs from other agencies. Our findings also emphasise the need for core specialist registrar and consultant continuing professional development updates in psychopharmacology.

Although in previous studies the participants felt that medication was underused (Bramble, 1997), this was not the case in our sample. In contrast, many psychiatrists were clearly uncomfortable about the increased use and it is of particular concern that the increase may be a reflection of pressure on community services in the region. The CAMHS appear to be under increasing pressure to manage social and behavioural problems as a result of inadequate provisions of social care and special educational services.

Finally, the overall increasing use of medication in child psychiatry may generate more referrals to adult mental health services, and subsequently lead to added pressure on adult resources as well.

\section{References}

AMAN, M. G., DE SMEDT, G., DERIVAN, LYNN, D. \& KING, B. H. (2002) A., et al (2002) Double-blind, placebocontrolled study of risperidone in the treatment of disruptive behaviors in children with subaverage intelligence. American Journal of Psychiatry, 159, 1337-1346

BRAMBLE, D. (1992) The use of antidepressants by British child psychiatrists. Psychiatric Bulletin, 16, 396-398.

— (1997) Psychostimulants and British child psychiatrists. Child Psychology and Psychiatry Review, 2, 159-162.

COGHILL, D. (2001)

Psychopharmacology. In Finding the Evidence, a Gateway to the Literature in Child and Adolescent Mental Health (eds A. Scott, M. Shaw \& C. Joughin), pp. 139-150. FOCUS project. London: The Royal College of Psychiatrists, Gaskell.

FINDLING, R. L., MCNAMARA, N. K., BRANICKY, L. A., et al (2000) A double blind pilot study of risperidone in the treatment of conduct disorder. Journal of the American Academy of Child \& Adolescent Psychiatry, 39, 509-516.

JAMES, A. C. (1996) A survey of the prescribing practices of child and adolescent psychiatrists. Child Psychology \& Psychiatry Review, 1 , 94-97.

JOHNSON, J. \& CLARK, A. F. (2001) Prescribing of unlicensed medicines or licensed medicines for unlicensed applications in child and adolescent psychiatry. Psychiatric Bulletin, 25 465-466.

KAPLAN, S. L., SIMMS, R. M. \& BUSNER, J. (1994) Prescribing practices of outpatient child psychiatrists. Journal of the American Academy of Child \& Adolescent Psychiatry, 33, 35-44. Aggressive behaviour. In Practical Child and Adolescent Psychopharmacology (ed. S. Kutcher), pp. 305-327. Cambridge: Cambridge University Press.

MCCRACKEN, J.T., MCGOUGH, J., SHAH, B., et al (2002) Risperidone in the treatment of children with autism and serious behavioral problems. New England Journal of Medicine, $\mathbf{3 4 7}$ 314-321.

MCNICHOLAS, F. (2001) Prescribing practices of child psychiatrists in the UK. Child Psychology \& Psychiatry Review, 1,94-97.

\section{OFFICE FOR NATIONAL STATISTICS}

(2000) Region in Figures. Department of Trade and Industry, HM Land Registry; Home Office. London: National Statistics.

POPPER, C.W. (2002) Child and adolescent psychopharmacology at the turn of the millennium. In Practical Child and Adolescent

Psychopatharmacology (ed. S. Kutcher), pp.1-37. Cambridge: Cambridge University Press.

RAM, J. R. \& VANSTRALLEN, M. (1999) Use of antipsychotics by child and adolescent psychiatrists (letter). Psychiatric Bulletin, 23, 182-183.

SAFER, D. J., ZITO, J. M. \& FINE, E. M. (1996) Increased methylphenidate usage for attention deficit disorder in the 1990s. Paediatrics, 98,10841088.

SLAVESKA, K., HOLLIS, C. \& BRAMBLE D. (1998) Use of antipsychotics by child and adolescent psychiatrists. Psychiatric Bulletin, 22, 685-687.

*Ursula Doerry Specialist Registrar in Child and Adolescent Psychiatry, Parkview Clinic, 60 Queensbridge Road, Moseley, Birmingham B13 8QE, Lindsey Kent Senior Lecturer, University of Birmingham 